\title{
0856 ADDRESSING CORRUPT ENFORCEMENT BY ROAD SAFETY OFFICERS ON NIGERIAN HIGHWAYS FOR FATALITY REDUCTION
}

B Okonkwo*, 0 Emmanuel, C C Ojugbana, I Ikediashi Correspondence: PATVORA Initiative, 24 Ojugbana Drive, Ezenei Avenue Box 505, Asaba, Delta State, Nigeria

10.1136/ip.2010.029215.856

Situation Despite the increased efforts of the Management of Nigeria's regulating agency on road safety to curb road traffic injuries through increased enforcement, violation of road safety rules is recorded by recent studies to be rampant. Most media reports on road safety have attributed road violation to poor education of road users and corruption among road safety officers at check points on the highways. Thus increasing road risks and dangers.

Objective To investigate corrupt enforcement practices by road safety officers and proffer suggestions.

Method Activities of four major checkpoints of the Federal Road Safety Commission (FRSC) of Nigeria were inspected in Imo, Anambra, Kaduna, kano and Delta states. Focus was on conspicuously defaulting drivers on over loading of vehicles with goods. Ten over loaded vehicles were randomly selected and discretely monitored at each checkpoint.

Findings The study revealed that in all checkpoints at least two in five vehicles that were stopped for over loading violation were not fined or booked due to acceptance of bribe by enforcement officers.

Conclusion Weak and corrupt enforcement is a major set back to achieving safer roads in Nigeria. Sensitisation and effective monitoring of enforcement officers is necessary to address the high rate of corruption that contributes to increased violation of traffic rules. Road users should be given opportunity to report erring enforcement officers and the national road safety 
agency should set up a quick response system to enable them obtain evidence from road users that are willing to report corrupt officers. 